\title{
Polyimide-Silica Hybrid Materials Based on p-Aminophenyltrimethoxysilane Terminated Poly(amic acid)s
}

\author{
Petr SySEL, ${ }^{\dagger}$ Roman PULEC, and Martin MARYŠKA* \\ Department of Polymers, Institute of Chemical Technology, \\ Technická 5, 16628 Prague 6, Czech Republic \\ * Department of Glass \& Ceramics, Institue of Chemical Technology, \\ Technická 5, 16628 Prague 6, Czech Republic
}

(Received February 21, 1997)

\begin{abstract}
Polyimide-silica hybrid materials with covalently bound phases were prepared via a sol-gel process. The starting materials were $p$-aminophenyltrimethoxysilane terminated poly(amic acid)s of controlled molecular weight ranging from 5000 to $10000 \mathrm{~g} \mathrm{~mol}^{-1}$ and tetramethoxysilane. Optical transparency of the final films increases with the number of bonds between phases. The dependence of the thermal and mechanical properties and morphology on the silica content and/or concentration of bonds between phases were studied.

KEY WORDS Poly(amic acid) / Polyimide-Silica Hybrid Materials / Sol-Gel Process /
\end{abstract}

Aromatic polyimides (PI) (Figure 1) exhibit outstanding dielectric and mechanical properties at elevated temperatures. ${ }^{1}$

Nevertheless, relatively high values of water sorption (up to $3-4 \mathrm{wt} \%$ ) and coefficients of thermal expansion $\left(\sim 5 \times 10^{-5} \mathrm{~K}^{-1}\right)$ impede (micro)electronic applications, e.g., forming stress-free films on silicon substrates. ${ }^{2}$ From this point of view silica $\left(\mathrm{SiO}_{2}\right)$, that exhibits very low values of water sorption (close to $0 \mathrm{wt} \%$ ) and coefficients of thermal expansion $\left(\sim 5 \times 10^{-7} \mathrm{~K}^{-1}\right)$, would be more suited for (micro)electronic applications but dielectric properties and planarizability are inferior to polyimides.

Combined materials exhibiting favourable properties of both polyimides and silica are therefore in great demand. However, a classical combination of these materials (filling, composites) leads to heterogeneous products not applicable to some purposes (e.g., optoelectronics).

In recent years increased attention has been paid to the preparation of highly homogeneous organic-inorganic hybrid materials via the sol-gel method. This procedure has also been utilized for the preparation of polyimide-silica hybrid materials.

The most direct route to these materials is hydrolysis and condensation of tetraalkoxysilane in a solution of a polyimide precursor [poly(amic acid) (Figure 1)] in $\mathrm{N}$-methyl-2-pyrrolidone or $\mathrm{N}, \mathrm{N}$-dimethylacetamide followed by thermal treatment. ${ }^{3}$ Due to the apparent macrophase separation, the resulting films with silica content of $5-8 \mathrm{wt} \%$ and above were found to be opaque and exhibit poorer mechanical properties compared to those of pure polyimides. Using the poly(amic acid) trimethylamine salt in methanol as the starting material the point of incipient opacity of the resulting films shifted to a higher level. ${ }^{4}$

Morikawa et al. ${ }^{5}$ prepared transparent films with high content of silica (up to $70 \mathrm{wt} \%$ ) by introducing into the polymer backbone ethoxysilyl groups which act as bonding sites for the silica. However, this is complicated and difficult to apply to large-scale production. In the work $^{6} p$-aminophenyltrimethoxysilane was added into a solution of poly(amic acid) in $N, N$-dimethylacetamide.

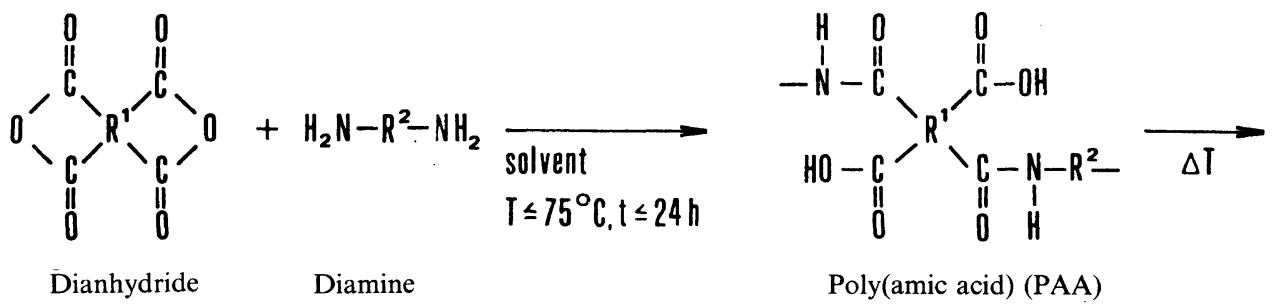

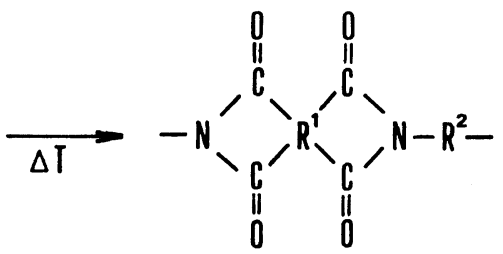

Polyimide (PI)

Figure 1. Synthesis of polyimides.

\footnotetext{
† To whom correspondence should be addressed.
} 

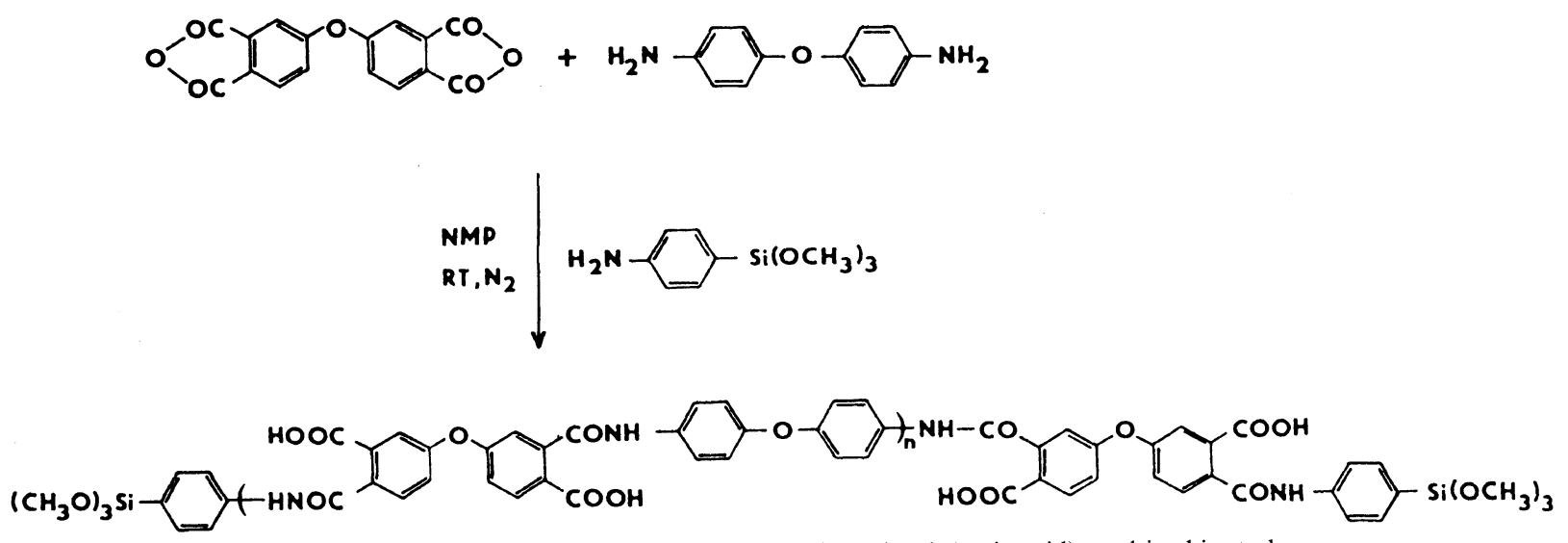

Figure 2. $p$-Aminophenyltrimethoxysilane terminated poly(amic acid) used in this study.

The compound undergoes hydrolysis and polycondensation along with tetraalkoxysilane while its amino groups react at high temperatures with the carboxylic acid groups in the poly(amic acid). However, the transformation of poly(amic acid) to polyimides is not complete and the properties may be inferior to those of fully imidized polyimides.

We suggest preparing polyimide-silica hybrid materials with covalently bound phases based on poly(amic acid)s terminated with commercially available $p$-aminophenyltrimethoxysilane ${ }^{7}$ (Figure 2). The controlled (defined) molecular weights of poly(amic acid)s govern the concentration of the bonds. In the present work we focus attention on the characterization of these materials.

\section{EXPERIMENTAL}

3,3'-Oxydiphthalic anhydride (ODPA) (Chriskev) was heated to $180^{\circ} \mathrm{C}$ overnight in a vacuum before use. 4,4'-Diaminodiphenylether (ODA) (Aldrich) was used as received. Tetramethoxysilane (TMOS) and $p$-aminophenyltrimethoxysilane (APTMS) (both ABCR) were used without further purification. $N$-Methyl-2-pyrrolidone (NMP) (Merck) was distilled under vacuum over phosphorus pentoxide and stored in an inert atmosphere.

p-Aminophenyltrimethoxysilane terminated poly(amic acid)s were prepared in a $250 \mathrm{ml}$ three-necked flask equipped with a mechanical stirrer, nitrogen inlet, and condenser with a drying tube.

A typical example of the synthesis of terminated poly(amic acid) of this type (with theoretical molecular weight $M_{n}=5000 \mathrm{~g} \mathrm{~mol}^{-1}$ ) is as follows:

$5 \mathrm{~g}(0.01612 \mathrm{~mol})$ ODPA was dissolved in $55.3 \mathrm{ml} \mathrm{NMP}$ and $0.7353 \mathrm{~g}(0.00345 \mathrm{~mol})$ of the endcapping agent (APTMS) was added (the weighing dish + funnel was rinsed with $10 \mathrm{ml} \mathrm{NMP)}$ to the reaction mixture and allowed to react with ODPA for 2 hours. $2.8823 \mathrm{~g}$ $(0.01439 \mathrm{~mol})$ ODA were then added $(10 \mathrm{ml}$ NMP used for rinsing) and the reaction was allowed to proceed at room temperature for 24 hours.

A calculated amount of tetramethoxysilane (TMOS) (to reach the desired silica content) was added directly to a $10 \mathrm{wt} \%$ solution of PAA in NMP under stirring. A stoichiometric amount of water per methoxy groups of TMOS was then added. The resulting homogeneous solution was poured onto a Teflon dish. After drying at $60^{\circ} \mathrm{C}$ for 24 hours, the film was heated 2 hours at $125^{\circ} \mathrm{C}$,
Table I. Transparent/opaque character of the prepared hybrid films

\begin{tabular}{|c|c|c|c|c|c|}
\hline \multirow{2}{*}{$\begin{array}{l}M_{n, \text { theor }}{ }^{\mathrm{a}} \\
\mathrm{g} \mathrm{mol}^{-1}\end{array}$} & \multicolumn{5}{|c|}{ Silica content $/ w t \%$} \\
\hline & 10 & 20 & 30 & 40 & 50 \\
\hline 5000 & $\mathrm{~T}^{\mathbf{b}}$ & $\mathrm{T}$ & $\mathrm{T}$ & $\mathrm{T}$ & $\mathrm{O}^{\mathrm{c}}$ \\
\hline 7500 & $\mathrm{~T}$ & $\mathrm{~T}$ & $\mathrm{O}$ & $\mathrm{O}$ & $\mathrm{O}$ \\
\hline 10000 & $\mathrm{~T}$ & $\mathrm{O}$ & $\mathrm{O}$ & $\mathrm{O}$ & $\mathrm{O}$ \\
\hline
\end{tabular}

${ }^{a}$ Theoretical molecular weight of $p$-aminophenyltrimethoxysilane terminated poly(amic acid). ${ }^{\mathrm{b}}$ Transparent. ${ }^{\mathrm{c}}$ Opaque.

2 hours at $200^{\circ} \mathrm{C}$ and, finally 5 hours at $300^{\circ} \mathrm{C}$.

The density of the prepared films was determined by a pycnometer. IR spectra were taken with a NICOLET 740 spectrometer. Dynamic thermogravimetric measurements were performed in air with a Du Pont 990 Thermal Analyzer, module 951 (heating rate 5, 10 , and $20^{\circ} \mathrm{C}$ $\min ^{-1}$, respectively), and DSC measurements with a Du Pont 2000 Thermal Analyzer, module $910\left(5^{\circ} \mathrm{C} \mathrm{min}{ }^{-1}\right)$. Tensile properties were measured with Instron 1122 at room temperature at drawing rate of $20 \mathrm{~mm} \mathrm{~min}^{-1}$. Film specimens about $50 \mu \mathrm{m}$ thick were measured. Scanning electron micrographs (SEM) were taken on crossections of the films covered with a thin gold layer using a JOEL $100 \mathrm{~B}$ (scanning mode) electron microscope.

\section{RESULTS AND DISCUSSION}

The most reactive tetraalkoxysilane-tetramethoxysilane (TMOS) - was used as the starting material for the non-catalyzed sol-gel process. The silica content in the hybrid materials was calculated assuming,

$$
\begin{aligned}
& \mathrm{Si}\left(\mathrm{OCH}_{3}\right)_{4}+4 \mathrm{H}_{2} \mathrm{O} \rightarrow \mathrm{Si}(\mathrm{OH})_{4}+4 \mathrm{CH}_{3} \mathrm{OH} \\
& \mathrm{Si}(\mathrm{OH})_{4} \rightarrow \mathrm{SiO}_{2}+2 \mathrm{H}_{2} \mathrm{O}
\end{aligned}
$$

proceeded to completion.

Our experiments showed that $p$-aminophenyltrimethoxysilane terminated ODPA-ODA poly(amic acid)s (Figure 2) with molecular weight $M_{\mathrm{n}}$ lower than 10000 $\mathrm{g} \mathrm{mol}^{-1}$ are suitable for preparing transparent hybrid materials with silica content higher than $10 \mathrm{wt} \%$. The optical transparency of the prepared products is given in Table I. This property improves with increasing concentration of bonds between phases. Hybrid films with silica content of $50 \mathrm{wt} \%$ and more were opaque but 
still showed self standing.

Thermogravimetry and density measurements (quantitatively) and IR spectroscopy (qualitatively) show thermal treatment (final phase $5 \mathrm{~h} / 300^{\circ} \mathrm{C}$ ) not to be sufficient to complete the sol-gel reactions. It is apparent that prolonged heating at higher temperatures after moderate drying (see Experimental section) reduces the amounts of volatiles escaping below the decomposition temperature of the hybrid materials. Samples treated at $300^{\circ} \mathrm{C}$ for 5 hours contained less than $5 \mathrm{wt} \%$ of such volatiles. From the extrapolated dependence of the density of hybrid materials on the silica content, the density of silica was found to be about $2 \mathrm{~g} \mathrm{~cm}^{-3}$ (theoretically it should be $2.2 \mathrm{~g} \mathrm{~cm}^{-3}$ ). The absorbance of the $\mathrm{Si}-\mathrm{O}-\mathrm{Si}$ asymmetric stretching vibration at 1013 $1018 \mathrm{~cm}^{-1}$ becomes more intensive during heating, while the absorbance of the $\mathrm{Si}-\mathrm{OH}$ stretching vibration at $930-940 \mathrm{~cm}^{-1}$ becomes weaker but it does not disappear fully.

The activation energies of $5 \mathrm{wt} \%$ thermooxidative degradation of the hybrid materials increased slightly with silica content (Table II). The residual ash (after $20-800^{\circ} \mathrm{C}$ thermal exposition) was almost proportional to inorganic content. The glass transition temperature $\left(T_{\mathrm{g}}\right)$ of these samples were nearly constant up to $30 \mathrm{wt} \%$ silica content. The restricted movement of the polyimide

Table II. Thermal and mechanical properties of polyimide-silica hybrid materials (prepared from poly(amic acid) with $M_{n}=5000 \mathrm{~g} \mathrm{~mol}^{-1}$ )

\begin{tabular}{lcrrrrr}
\hline & \multicolumn{6}{c}{ Silica content $/ \mathrm{wt} \%$} \\
\cline { 2 - 7 } & 0 & 10 & 20 & 30 & 40 & 50 \\
\hline$E_{\mathrm{A}}{ }^{\mathrm{a}} / \mathrm{kJ} \mathrm{mol}^{-1}$ & 110 & 156 & 193 & 215 & 230 & 240 \\
$T_{\mathrm{g}}^{\mathrm{b}} /{ }^{\circ} \mathrm{C}$ & 190 & 192 & 188 & 194 & 219 & 225 \\
Tensile strength/MPa & $120^{\mathrm{c}}$ & 118 & 51 & 46 & - & - \\
Elongation at break/\% & $8,9^{\mathrm{c}}$ & 6,7 & 2,6 & 2,3 & - & - \\
Tensile modulus/GPa & $2,1^{\mathrm{c}}$ & 2,4 & 2,4 & 2,6 & - & - \\
\hline
\end{tabular}

${ }^{a}$ Activtion energy. $\quad{ }^{\mathrm{b}}$ Glass transition temperature. $\quad{ }^{\mathrm{c}}$ ODPA-ODA polyimide with uncontrolled molecular weight.

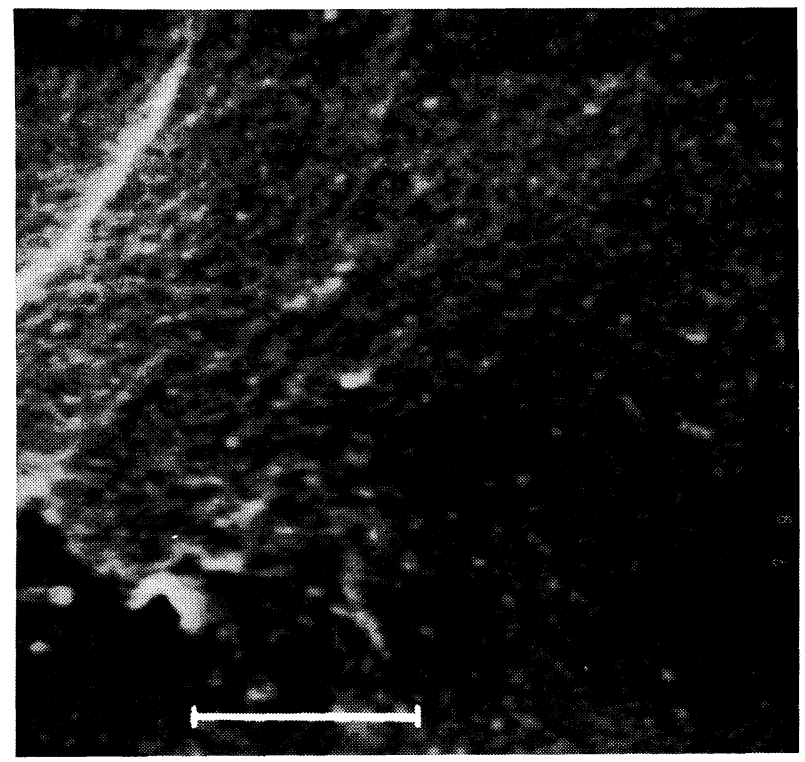

(a) chains at the higher silica amounts was reflected in the rise in $T_{\mathrm{g}}$ (Table II).

The tensile strength and elongation at break of the hybrid films decreased with increasing silica content and the tensile modulus increased slightly (Table II).

Thermal and mechanical properties were influenced by the concentration of the bonds between phases insignificantly (for hybrid films based on poly(amic acid)s with $M_{n}=5000$ and $7500 \mathrm{~g} \mathrm{~mol}^{-1}$ at the same content of silica).

Scanning electron micrographs of the hybrid films are shown in Figures $3 a-c$. A reasonably good adhesive

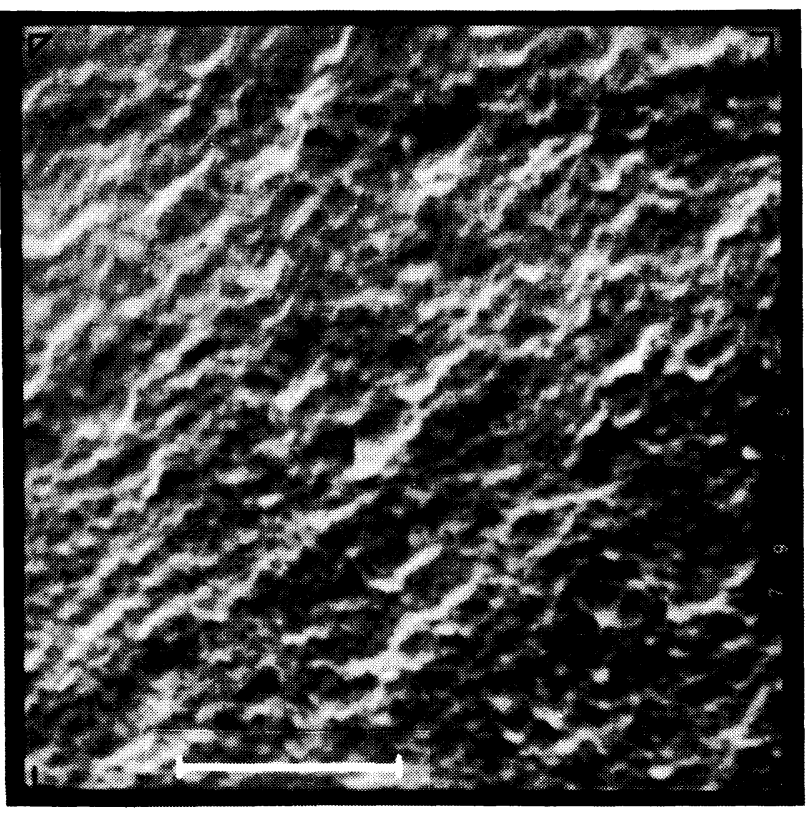

(b)

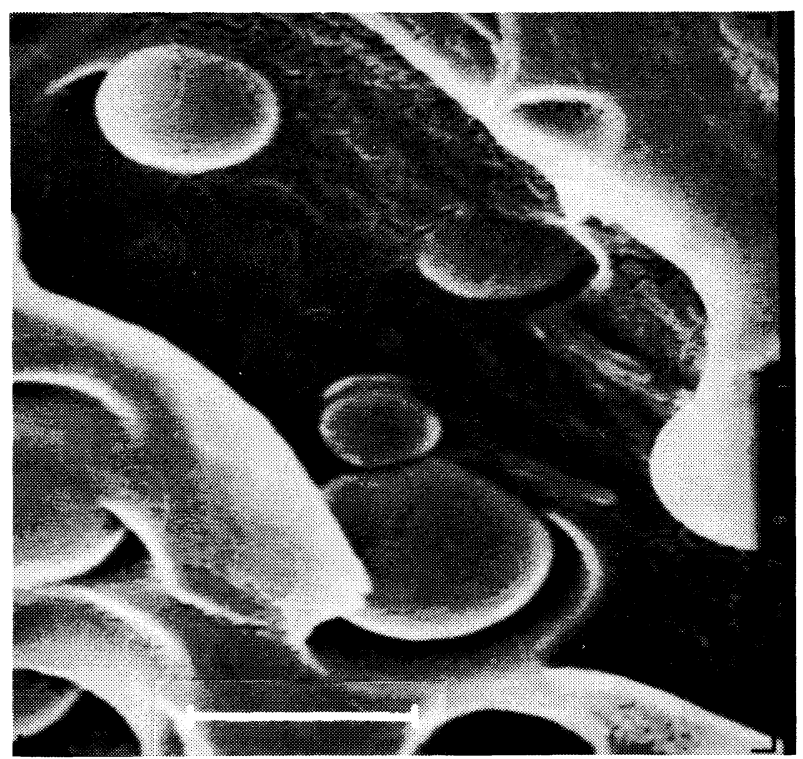

(c)

Figure 3. Scanning electron microscopic photographs of the polyimide-silica hybrid films based on: (a) p-aminophenyltrimethoxysilane terminated poly(amic acid) with $M_{n}=5000 \mathrm{~g} \mathrm{~mol}^{-1}$ and a silica content of $10 \mathrm{wt} \%$ (bar $=1 \mu \mathrm{m})$; (b) $p$-aminophenyltrimethoxysilane terminated poly(amic acid) with $M_{n}=5000 \mathrm{~g} \mathrm{~mol}^{-1}$ and a silica content of $30 \mathrm{wt} \%$ (bar $=1 \mu \mathrm{m})$; (c) poly(amic acid) with uncontrolled $M_{n}$ at silica content of $10 \mathrm{wt} \%(\mathrm{bar}=1 \mu \mathrm{m})$. 
interface between the polyimide and silica phase (particles with diameter $0.1 \mu \mathrm{m}$ ) was observed in the hybrid films based on the terminated poly(amic acid) with $M_{\mathrm{n}}=5000$ $\mathrm{g} \mathrm{mol}^{-1}$ (Figures 3a, b). Silica particles with diameter of $0.75-1 \mu \mathrm{m}$ were evidently separated from the polyimide matrix when no bonds were formed between the phases (Figure 3c).

A detailed study of the thermal expansion coefficient and water sorption of these hybrid materials is to be made.

Acknowledgment. This work was supported by the Grant Agency of the Czech Republic (project 203/96/ 1378).

\section{REFERENCES}

1. C. A. Sroog, Progr. Polym. Sci., 16, 561 (1991).

2. S. Numata and N. Kinjo, Polym. Eng. Sci., 28, 906 (1988).

3. A. Morikawa, Y. Iyoku, M. Kakimoto, and Y. Imai, Polym. J., 24, 107 (1992).

4. A. Morikawa, H. Yamaguchi, M. Kakimoto, and Y. Imai, Chem. Mater., 6, 913 (1994).

5. A. Morikawa, Y. Iyoku, M. Kakimoto, and Y. Imai, J. Mater. Chem., 2, 679 (1992).

6. S. Wang, Z. Ahmad, and J. E. Mark, Chem. Mater., 6, 943 (1994).

7. P. Sysel and R. Pulec, "Preparation of Polyimide-Silica Hybrid Materials via a Sol-Gel Process," 4th European Technical Symposium on Polyimides \& High Performance Polymers, Montpellier, May 13-15, 1996, organized by Laboratory of Polymer Science and Advanced Organic Materials (LEMP/ MAO), University of Motpellier 3, France, PI 3-5. 